none of the donors had peculiarly strong lytic activity against normal red cells and suggest that haemolysis might have occurred even with ABO compatible platelet concentrates. The presence of activated complement in donor plasma or complement activation in the recipient by immune reactions against platelet or white cell antigens ${ }^{1}$ could explain lysis of the PNH clone.

The behaviour of this case highlights the danger of even small plasma transfusions in some patients with $\mathrm{PNH}$, and the in vitro studies raise the possibility that such life threatening complications might occur with ABO compatible plasma. It may be premature to abandon the washing of all but those blood components containing $\mathrm{ABO}$ incompatible plasma when transfusing patients with $\mathrm{PNH}$. Clearly, even platelet concentrates from $\mathrm{ABO}$ incompatible donors can prove dangerous and, despite the difficulties involved, should be washed. It will need only one documented case of haemolysis following transfusion of ABO compatible plasma to convert a "myth" into fact. We shall not challenge our patient with $\mathrm{ABO}$ compatible plasma in an attempt to provide that case.

We thank Dr P W G Saunders for the serological investigations which first showed lytic activity in the platelet donor plasma.

1 Rotoli B, Luzzatto L. Paroxysmal nocturnal haemoglobinuria. Baillière's clinical haematology. 1989;i:113-8.

2 Dacie JV. Paroxysmal nocturnal haemoglobinuria. In Weatherall DJ, Ledingham JGG, Warrell DA, eds Oxford textbook of medicine. Oxford: Oxford University Press, 1987:1954.

3 Dacie JV. Transfusion of saline-washed red cells in nocturnal haemoglobinuria (Marchiafava-Micheli disease). Clin Sci 1948;7:65-75.

4 Brecher ME, Taswell HF. Paroxysmal nocturnal hemoglobinuria and the transfusion of washed red cells. A myth revisited. Transfusion 1989;29:681-5.

5 Najean Y, Haguenauer O for the Cooperative Group for the Study of Aplastic and Refractory Anemias. Long-term (5 to 20 years) evolution of nongrafted aplastic anemias Blood 1990;76:2222-8.

\title{
Frequency of glove puncture in the post mortem
} room

\author{
J Weston, G Locker
}

\begin{abstract}
The post mortem room is a potential source of danger from contamination caused by glove punctures. The objective of this study was to assess the incidence of hand injury and hand contamination during post mortem examinations. A prospective study of injury and glove puncture rate was conducted during post mortem examinations performed in 1990 on adults in Northwick Park Hospital mortuary. Four pathologists and two assistants performed a total of 44 post mortem examinations on adults. All participants completed a questionnaire after each examination, recording the total number of gloves used and the number of hand injuries and glove perforations sustained. Just over $8 \cdot 3 \%$ of gloves were punctured; $31 \cdot 8 \%$ of these punctures went unnoticed. Evisceration was the procedure most likely to result in hand contamination.

The study highlights a significant risk which could be reduced by more care, frequent glove changes, and hand washing during post mortem examinations. In particular, gloves should be changed and hand washed when evisceration has been completed.
\end{abstract}

The protection of medical laboratory workers is of great importance and many precautionary measures have found their way into standard medical laboratory practice. One obvious safety measure is the donning of gloves before handling fresh human tissue.

The post mortem room is a potential source of danger to both pathologists and their assistants. Because pathologists are not required to protect patients from infection in the same way as surgeons are, they may neglect to protect themselves against contamination during post mortem examinations.

Like surgeons, pathologists use sharp instruments in the presence of free body fluids. Thus if they are injured they may run similar risks of contamination. Furthermore, a glove may be punctured in the course of a post mortem examination without actually incurring an injury, but a pre-existing skin lesion may become contaminated. This second risk may be compounded if the puncture goes unnoticed so that the glove is not changed and the hand not washed for some time. In particular, evisceration of the cadaver involves the use of sharp instruments and may expose jagged edges of bone that are potential sources of danger.

To quantify these risks, glove punctures and hand injuries were recorded during post mortem examinations of adults. The relative risk of the evisceration procedure was also assessed.

\section{Methods}

Four pathologists and two technicians took part in the study. One of the pathologists was of consultant grade with over 20 years of post mortem examination experience. The other three were juniors with between one and five
Correspondence to: J Weston Accepted for publication 31 July 1991 
Summary of results

\begin{tabular}{|c|c|c|c|c|}
\hline & Number & Rate & $\chi^{2}$ test & Significance \\
\hline $\begin{array}{l}\text { Total number of post mortem examinations } \\
\text { Total gloves used } \\
\text { Punctures } \\
\text { Unused gloves } \\
\text { Punctures }\end{array}$ & $\begin{array}{r}\frac{44}{262} \\
22 \\
225 \\
1\end{array}$ & $\begin{aligned} & 0.080 \\
& 0.004\end{aligned}$ & 2 & p $<0.001$ \\
\hline $\begin{array}{l}\text { Eviscerated by technicians } \\
\text { Gloves worn by technician } \\
\text { Punctures by technician } \\
\text { Gloves worn by Drs } \\
\text { Punctures by Drs }\end{array}$ & $\begin{array}{r}\frac{12}{45} \\
10- \\
76 \\
5\end{array}$ & . & & $p<0.05$ \\
\hline
\end{tabular}

years of experience. Likewise, one of the technicians was fully trained with 13 years of experience, while the other was a trainee with one year's experience.

Forty four post mortem examinations of adults were assessed. Those involved in each post mortem completed a questionnaire stating: how many gloves they used; how many injuries they sustained; how many glove punctures they noticed; and how many they discovered incidentally by filling the glove with tap water under pressure after they had taken them off.

Twelve of the cadavers were eviscerated by a technician. The remainder were eviscerated by the pathologist.

At the end of the experimental period, the total number of gloves was added up and a similar number of unused gloves were tested for punctures by filling with tap water under pressure.

The total number of gloves used by each person involved and the number of injuries and punctures were calculated. The following assessments were considered: (i) The overall puncture rate was compared to the puncture rate in unused gloves; (ii) the puncture rate in gloves worn by pathologists was compared with that of technicians in those 12 post mortem examinations where the technician had performed the evisceration.

The $\chi^{2}$ test was calculated on the results. Confidence limits of less than $5 \%$ were considered significant.

\section{Results}

Incidence of infection in cadavers: None of the 44 cadavers was known to have positive serology for hepatitis B or human immunodeficiency virus. One was being treated for tuberculosis at the time of death.

Glove punctures and injuries: Two injuries were sustained, both by pathologists, one during evisceration and the other during slicing of the liver. Both injuries were to the non-dominant hand. Neither required sutures.

Comparison of puncture rate in used and unused gloves: A total of 262 gloves were used: 22 glove punctures were sustained $(8.3 \%)$, of which seven went unnoticed until the glove was filled with water $(31.8 \%)$ (table).

Of 225 unused gloves, one had a large hole in it $(0.4 \%)$. Thus $\chi^{2}=17.02 ; p<0.001$. The average rate of glove puncture at post mortem examination was 0.5 (table).

Comparison of puncture rate in eviscerators and prosectors: In the 12 cadavers eviscerated by technicians 10 punctures were sustained in a total of 45 gloves (22\%), while the pathologist sustained five punctures in a total of 76 gloves $(6.6 \%)$. Thus $\chi^{2}=15.3 ; p<0.001$ (table).

\section{Discussion}

Only one of the post mortem examinations considered afforded a known risk of contamination (from tuberculosis). A significant number of glove punctures occurred, however, $(8.3 \%$; p $<0.001)$ at a rate of $0.5 /$ exam. Of these $31.8 \%$ went unnoticed. The magnitude of these results compare with those found during assessment of surgical procedures. ${ }^{1}$ Although gloves are impermeable to HIV and hepatitis $B$, punctured gloves are not. Pathologists have also contracted tuberculosis as a result of hand wounds. ${ }^{2}$

Two injuries were sustained during the course of the experimental period. Both were relatively minor and were treated in accordance with current laboratory safety recommendations. ${ }^{34}$ The results presented here, however, show that evisceration is an especially risky procedure in terms of glove puncture. Many of these punctures went unnoticed. In these instances a pre-existing hand lesion may be bathed in infected material for several hours (because evisceration is the first procedure in the post mortem examination) and never treated according to current safety procedures. The risk of contamination from a puncture without concurrent injury may therefore be greater than a puncture associated with an injury.

The findings highlight a significant risk to mortuary workers which could be reduced in several ways. Education of both pathologist and technician is important to promote awareness of this risk. It has been suggested that double gloving reduces the risk of hand contamination to surgeons. ${ }^{5}$ We performed a smal number of post mortem examinations wearing two pairs of gloves; in contrast to the findings of Gerberding et $a l,{ }^{4}$ no significant protection was afforded.

In conclusion, the most important way of reducing the risk associated with glove punctures in the motuary should be frequent glove changes and hand washing throughout the post mortem examination to reduce the risk of contamination as a result of unnoticed glove punctures. In particular, gloves should be changed and hands washed at the end of the evisceration procedure.

Thanks are due to AB Price, C Quinn, PS Ong and D Bishop fo completing questionnaires at the end of post mortem examinations.

1.Dodds RDA, Guy PJ, Peacock AM, Duffy SR, Barke SGE,Thomas MH. Surgical glove perforation. Br J Sur 1988;75:966-8.

2 Goette DK, Jacobson KW, Doty RD. Primary inoculation tuberculosis of the skin. Arch Dermatol 1978;114:567-9.

3 Howie AJ. Code of practice for the prevention of infection in clinical laboratories and post mortem rooms. London: HSE HMSO, 1978:37.

4 Health Services Advisory Committee. Safety in Health Service laboratories. Safe working and the prevention of infection in the mortuary

5 Gerberding JL, Littel C, Tarkingston A, Brown A, Schecter WP. Risk of exposure of surgical personnel to patients' blood during surgery at San Francisco General Hospital. N Engl J Med 1990;322:1788-93. 